\title{
REGIONAL VARIATIONS IN THE SOCIAL PREFERENCE FUNCTION BETWEEN INFLATION AND UNEMPLOYMENT
}

\author{
David J. Smyth and Susan Washburn Taylor*
}

\begin{abstract}
In this paper we estimate presidential popularity functions for four regional subsets using a quadratic in inflation and unemployment. Popularity functions for the East, West, South, and Midwest are estimated by seemingly unrelated regressions using Gallup poll data for the Reagan administration. Through the use of a J-test, we establish that regional participants generally respond to national inflation and unemployment rates rather than regional macroeconomic statistics when assessing presidential performance. We also explore, through the use of a Wald test, differences in responses to macroeconomic fluctuations between the four regional groups. On the whole, we find surprising homogeneity in the preference functions across regions.
\end{abstract}

\section{INTRODUCTION}

In this paper we estimate presidential popularity functions utilizing monthly Gallup Poll data for the Reagan administration for four regional subsets: East, Midwest, South, and West. These estimates yield regional social preference functions between inflation and unemployment. We estimate the presidential popularity function as a quadratic in inflation and unemployment; this allows us to derive indifference curves between inflation and unemployment that are concave to the origin as predicted by economic theory. 1

Section II below explains the data, the model and estimation procedures. In section III, we explore whether people react to the inflation and unemployment rates in their region or to the national rates. In section IV we conduct rigorous tests to determine if economic perceptions are significantly different across regions. Our conclusions are summarized in section V.

\section{THE DATA AND THE MODEL}

We employ the following variables in our analysis of presidential popularity disaggregated by region:

\footnotetext{
*Louisiana State University and Kansas State University, respectively. Smyth's research was supported by the LSU Foundation. We are grateful for the comments of two referees. Any errors are our responsibility.
} 
POP = presidential popularity in each of the four regions: East, West,

South, and Midwest;

$\mathrm{P}=$ inflation rate;

$\mathrm{U}=$ national unemployment rate;

Honey $=$ dummy trend variable representing a president's initial honeymoon

period with the public;

Iran = binary dummy reflecting the Iran-Contra affair; and

$\varepsilon=$ disturbance term.

The presidential popularity data employed as the dependent variable is the percentage who responded "approve" to the Gallup Poll question "Do you approve or disapprove of the way Mr. is handling the job of President?" The Gallup organization provides data for four geographical regions: East, Midwest, South, and West. ${ }^{2}$ We utilize monthly data for the Reagan administration, 1981:21986:7, and 1987:1-1987:9 giving us 75 observations. Gallup data disaggregated by region are not available for the remainder of Reagan's second term.

Reagan's lowest popularity ratings came in January of 1983 when national unemployment reached its highest level during his two terms. At this time his popularity ranged from a low of $33.6 \%$ in the East to a high of $37.6 \%$ in the West. His highest popularity ratings by region were as follows: East, 69\% (1985:5); Midwest, 70\% (1981:5); South, 72\% (1985:8); and West, 68\% (1981:5).

Because we employ monthly data, we include as a regressor a lagged endogenous variable to account for the dynamic adjustment process. Due to the inclusion of the lagged dependent variable, we exclude 1981:1 and 1986:12.

The inflation rate, $P$, is the inflation rate over the past twelve months calculated from the consumer price index (all urban consumers, all items), expressed as a percentage. The unemployment measure, $\mathrm{U}$, is the percentage of unemployed civilian workers 16 years and older, seasonally adjusted. Both $P$ and $U$ are lagged one month to represent the most recent information known to the public.

A question of interest is whether individuals base their approval rating of a President on regional or national economic conditions. To address this issue, we use regional unemployment and inflation figures. From monthly Bureau of Labor Statistics (BLS) state employment data, we construct regional unemployment rates which encompass the same states as the Gallup regional data.

Regional inflation rates are available from the BLS on a bimonthly basis. To create a monthly series, we take the average of the preceding and following values for the missing data point. There are slight differences in the states included in the BLS division and the Gallup division but these differences are relatively minor. ${ }^{3}$ 
Since the BLS does not report CPI data for each individual state, a grouping wholly consistent with the Gallup division is not possible.

We include a honeymoon variable, Honey, to indicate that the public does not hold an incoming president responsible for the economic conditions which he inherited from his predecessor. This trend variable takes the value of 11 in 1981:2 and declines to 1 in 1981:12, taking the value of 0 thereafter.

Finally, to allow for the public's dissatisfaction with the Iran-Contra affair, we add an additional dummy variable, Iran, which takes the value of 0 until November 1986 and the value 1 in December 1986 and in all following months. ${ }^{4}$

The basic model to be estimated for each region is as follows:

$$
P O P=\delta\left(\beta_{0}+\beta_{1} P^{2}+\beta_{2} U^{2}+\beta_{3} \text { Honey }+\beta_{4} \text { Iran }\right)+(1-\delta) P_{-1}+\varepsilon,
$$

where POP and $\delta$ represent the dependent variable and adjustment processes respectively for the four regions. Two features about this model specification are noteworthy. First, the model is estimated as a quadratic in inflation and unemployment. This allows the resulting social indifference curve between inflation and unemployment to be concave to the origin. Lipsey (1965), Peston (1984), Nordhaus (1975), MacRae (1977) and Barro and Gordon (1983) provide theoretical support for the concave social indifference curve. Smyth and Dua (1988, 1989), Smyth, Washburn, and Dua (1989) and Smyth, Taylor, and Dua (1990) make use of this and other nonlinear specifications of the function. Second, we estimate the adjustment process, $\delta$, directly. This allows the $\beta_{i}$ coefficients to be the equilibrium values which exist after the partial adjustment process has been completed. Hypothesis tests may be applied directly to these equilibrium values.

The model is estimated within a seemingly unrelated regressions (SUR) framework. We choose this estimation technique because it is likely that disturbances in the different equations at a given time reflect some common unmeasurable or omitted factors, thus exhibiting contemporaneous correlation. SUR estimation is superior in this case because it uses information on explanatory variables that are included in the system but excluded from the individual equations; thus we gain in efficiency by joint estimation. ${ }^{5}$

\section{THE CHOICE OF AN INFLATION AND UNEMPLOYMENT RATE}

Before we estimate region-specific responses to changes in inflation and unemployment we explore whether people form their opinion of a President's performance based upon the unemployment and inflation rates relevant to their geographical area, the regional rates, or the national inflation and unemployment 
rates. To determine the appropriate inflation and unemployment rates, we conduct a non-nested test, the J-test, initially under the null hypothesis that the national measures are correct and thus that (1) represents the social preference function. The alternative hypothesis is that the regional rates are appropriate, and the social preference function may then be expressed as

$$
\begin{aligned}
P O P= & \delta\left(\beta_{0}+\beta_{1} \text { Regional } P^{2}+\beta_{2} \text { Regional } U^{2}+\beta_{3} \text { Honey }+\right. \\
& \left.\beta_{4} \text { Iran }\right)+(1-\delta) P_{-1}+\varepsilon .
\end{aligned}
$$

In conducting this test, the dependent variable is regressed on the explanatory variables of the null hypothesis, together with the fitted values from the regression associated with the alternative hypothesis. If the fitted values are significantly different from zero, the null hypothesis is rejected; otherwise, the null hypothesis cannot be rejected. The roles of the null and alternative hypotheses are reversed and the test is repeated to allow the original alternative hypotheses to be either rejected or accepted.

Table 1 presents the results of the non-nested tests for the appropriate inflation and unemployment rates. The first row presents results for the original null hypothesis. This hypothesis cannot be rejected for the East, Midwest, and South but is rejected for the West. The null hypothesis that regional economic terms should be included in the social preference function is rejected for all regions. Thus, the national rates are strictly preferred for all regions but the West. ${ }^{6}$

TABLE 1

J-Test for Appropriate Inflation and Unemployment Rates

Null Hypothesis

J-test Statistic

\begin{tabular}{lcccc} 
& East & Midwest & South & West \\
\hline $\begin{array}{l}\text { National P and U } \\
\text { Appropriate }\end{array}$ & 0.240 & 1.207 & 0.721 & $4.989^{*}$ \\
$\begin{array}{l}\text { Regional P and U } \\
\text { Appropriate }\end{array}$ & $9.677^{*}$ & $7.491^{*}$ & $11.587^{*}$ & $13.137^{*}$ \\
& & & &
\end{tabular}

*Indicates significance at the $5 \%$ level. 


\section{A COMPARISON OF RESPONSES BY REGION}

Applying maximum likelihood SUR to the four regional groups based upon equation 1 for the first Reagan term yields the results presented in Table 2. Though the preceding section indicates some ambiguity with respect to the economic measures to be used in the West, we include the national unemployment rate in this analysis because its use allows us to make direct comparisons across regions. The Durbin $\mathrm{m}$-statistics indicate no presence of serially correlated errors. ${ }^{7}$ For each region, including the West, the national unemployment and inflation coefficients are highly significant and have the anticipated sign.

TABLE 2

Disaggregation by Region

(t-statistics in parentheses )

\begin{tabular}{|c|c|c|c|c|}
\hline & East & Midwest & South & West \\
\hline Intercept & $\begin{array}{c}79.79 \\
(23.66)\end{array}$ & $\begin{array}{c}77.77 \\
(33.53)\end{array}$ & $\begin{array}{c}85.20 \\
(44.51)\end{array}$ & $\begin{array}{c}78.71 \\
(34.73)\end{array}$ \\
\hline Inflation & $\begin{array}{c}-0.17 \\
(-3.60)\end{array}$ & $\begin{array}{c}-0.11 \\
(-3.39)\end{array}$ & $\begin{array}{c}-0.15 \\
(-5.77)\end{array}$ & $\begin{array}{c}-0.13 \\
(-4.09)\end{array}$ \\
\hline Unemployment & $\begin{array}{c}-0.36 \\
(-8.20)\end{array}$ & $\begin{array}{c}-0.32 \\
(-10.38)\end{array}$ & $\begin{array}{c}-0.39 \\
(-15.55)\end{array}$ & $\begin{array}{c}-0.29 \\
(-9.82)\end{array}$ \\
\hline Honeymoon & $\begin{array}{c}2.15 \\
(3.25)\end{array}$ & $\begin{array}{c}1.75 \\
(3.87)\end{array}$ & $\begin{array}{c}1.79 \\
(4.89)\end{array}$ & $\begin{array}{c}1.75 \\
(3.88)\end{array}$ \\
\hline Iran & $\begin{array}{l}-16.11 \\
(-5.44)\end{array}$ & $\begin{array}{c}-14.93 \\
(-7.30)\end{array}$ & $\begin{array}{c}-14.41 \\
(-8.53)\end{array}$ & $\begin{array}{c}-18.16 \\
(-9.13)\end{array}$ \\
\hline Adjustment & $\begin{array}{c}0.44 \\
(5.86)\end{array}$ & $\begin{array}{c}0.64 \\
(7.41)\end{array}$ & $\begin{array}{c}0.71 \\
(8.68)\end{array}$ & $\begin{array}{c}0.57 \\
(6.90)\end{array}$ \\
\hline Adjusted $\mathrm{R}^{2}$ & 0.86 & 0.83 & 0.89 & 0.85 \\
\hline Durbin m-statistic & 0.380 & -0.236 & 1.548 & -0.484 \\
\hline Slope $\left(-\beta_{2} / \beta_{1}\right)$ & -2.18 & -3.01 & -2.70 & -2.33 \\
\hline
\end{tabular}

*All coefficients are significant at the $5 \%$ level. 
A visual inspection of the macroeconomic coefficients reveals that responses across regions appear to be similar. Are the differences in the coefficients across regions significant? We test the null hypothesis that cross-equation coefficients are equal by the Wald test, a chi-square test with degrees of freedom equal to the number of restrictions. ${ }^{8}$ Table 3 presents the chi-square results of tests for equality of coefficients across geographical regions. The cell in the first row, first column of the grid presents results of pairwise tests between East and West; the cell in the first row, second column compares East and Midwest and so forth. The null hypothesis for each chi square value is given in the far right hand column of the table. For example, the first figure in each cell represents the test statistic for the null hypothesis that intercepts are equal; the second figure is the statistic for the null hypothesis that the inflation coefficients are equal, and so forth.

TABLE 3

Chi-Square Values by Region

\begin{tabular}{lllll}
\hline \hline & West & Midwest & South & \\
\hline \multirow{2}{*}{ East } & 0.08 & 0.38 & 3.45 & Intercept \\
& 0.60 & 1.80 & 0.25 & Inflation \\
& 1.95 & 1.02 & 0.73 & Unemployment \\
& 1.49 & $3.85^{*}$ & $8.53^{*}$ & Adjustment \\
& 0.03 & 0.83 & 0.54 & Slopes \\
West & & & & \\
& & 0.09 & $6.00^{*}$ & Intercept \\
& & 0.22 & 0.31 & Inflation \\
& & 0.39 & $8.49^{*}$ & Unemployment \\
& & 0.33 & 1.60 & Adjustment \\
Midwest & 0.40 & 0.24 & Slopes \\
& & & & \\
& & & $11.48^{*}$ & Intercept \\
& & & 1.85 & Inflation \\
& & & $6.76^{*}$ & Unemployment \\
& & & 0.51 & Adjustment \\
& & & 0.16 & Slopes
\end{tabular}

*Indicates significant differences at the significance level $\alpha=.05$. The degrees of freedom for the null hypothesis that all coefficients are equal is 6 . For all other null hypotheses, the degrees of freedom is 1 .

We first examine the pairwise hypothesis that intercepts are equal. This null hypothesis is rejected only when the South is involved. Reagan's popularity was higher in the South than in the West or Midwest at the 5 percent significance level and higher than his approval rating in the East at the 10 percent level. 
The macroeconomic coefficients in Table 2 are quite similar. Although the inflation coefficient for the East is larger than that for the other regions, the chisquare values in Table 3 indicate that for all comparisons the difference in inflation values is not statistically significant. With respect to unemployment, again it is the South which differs from responses in other regions. In absolute terms, the South's response to increases in unemployment is larger than that in any other region. The chi-square values in Table 3 indicate that this difference is significantly larger at the 5 percent level for comparisons with the West and with the Midwest.

Although the values of the unemployment coefficients for the South and other regions differ significantly, the slopes of the indifference curve between inflation and unemployment for the regions are not. From (1), $d P / d U=-\beta_{2} U / \beta_{1} P$ is the slope of an indifference curve. At any point, the value of U/P is given so we can test the equality of slopes for any pair of regions by testing that the ratio $-\beta_{2} / \beta_{1}$, given for each region in Table 2 , are equal. The final figure in each cell in Table 3 gives the test statistic for slopes. We cannot reject the null hypothesis that the slopes are equal for any pair of regions.

\section{v. CONCLUSIONS}

Our analysis has provided an examination of regional perceptions toward President Ronald Reagan. We have established that regional participants, with the possible exception of the West, responded to the national unemployment and inflation rates rather than regional macroeconomic statistics when assessing presidential performance. We also explored differences in responses to macroeconomic fluctuations between the four regional groups. We found that Reagan's popularity base in the South was significantly larger than in any other region, but that Southemers punished him significantly more severely for increases in unemployment than did their counterparts in other regions. On the whole we found surprising homogeneity in the preference functions across regions.

\section{ENDNOTES}

1. Other studies of interest include Mueller (1970), Kernell (1978), Frey and Schneider (1978), Golden and Poterba (1980), Shapiro and Conforto (1980), MacKuen (1983), Norpoth and Yantek (1983), Chappell (1983), Chappell and Keech (1985a, 1985b), Ostrom and Simon (1985), Smyth and Dua (1988, 1989), Smyth, Washburn, and Dua (1989), and Smyth, Taylor and Dua (1990). Many economists 
and political scientists have examined the relationship between the macroeconomy and presidential popularity at the aggregate level. The only study which examines regional approval ratings is Monroe (1984). Most of her coefficients are insignificant, probably for two reasons: first, multicollinearity between the four economic measures included in the regression analysis; second, because she estimates one popularity function across several presidential regimes-Smyth, Washburn, and Dua (1989) find it necessary to estimate the function in a manner which allows coefficients to vary for each administration.

2. Those states classified as "east" are ME, NH, VT, MA, RI, CT, NY, NJ, $\mathrm{PN}, \mathrm{MD}, \mathrm{DE}, \mathrm{WV}$, and Washington D.C. The midwestern states are $\mathrm{OH}, \mathrm{MI}, \mathrm{IN}$, IL, WI, MN, IA, MO, ND, SD, NE, and KS. Southern states include VA, NC, SC, GA, FL, KY, TN, AL, MS, AR, LA, OK, and TX. Finally, western states are MT, AZ, CO, ID, WY, UT, NV, NM, CA, OR, WA, AK, and HI. The analysis might be more meaningful if smaller regional units were used. However, the Gallup data set is the only source of regional approval ratings available and it is only disaggregated by the four large regions.

3. The BLS and Gallup divisions for "West" and Midwest" are identical. The BLS classification of states in the Northeast is smaller than the corresponding "East" category used in Gallup analysis. Gallup includes MD, DE, WV, and Washington, D.C. as "East" while the BLS classifies these states as "South."

4. Alternative specifications of Honey and Iran were employed in preliminary research. These alternative specifications did not change the results presented here.

5. All estimations are conducted in Time Series Processor (TSP) and the nonlinear seemingly unrelated regression system is estimated by maximum likelihood.

6. The results for the West suggest that both models are misspecified and that both national and regional measures should be included; however the J-test results for the other regions favor national over regional rates. A series of likelihood ratio tests indicate that any combination of the regional rates may be excluded from a model which includes all four measures (the full model) with no significant difference in the likelihood ratio value. However, the full model is significantly superior to a model which excludes either or both of the national rates. This highlights the importance of the national measures but does not aid in explaining the different behavior of the West.

7. A description of the test is presented in Kmenta (1986, p. 333).

8. See Kmenta (1986, p. 492) for a detailed discussion of this test. 


\section{REFERENCES}

Barro, Robert G. and David B. Gordon. "A Positive Theory of Monetary Policy in a Natural Rate Model." Journal of Political Economy. 91 (1983). 589-610. Chappell, Henry W. "Presidential Popularity and Macroeconomic Performance: Are Voters Really So Naive?" Review of Economics and Statistics. 65 (1983). 385-392.

Chappell, Henry W. and William R. Keech. "A New View of Political Accountability for Economic Performance." American Political Science Review. 77 (1985a). 10-17. and "The Political Viability of a Rule-Based Monetary Policy." Public Choice. 46 (1985b). 125-140. and "Some Non-nested Hypotheses Tests and the Relations Among Them." Review of Economic Studies. (1982). 551-565.

Frey, Bruno S. and Friedrich Schneider. "An Empirical Study of Politico-Economic Interaction in the United States." Review of Economics and Statistics. 60 (1978). 174-183.

Golden, David G. and James M. Poterba. "The Price of Popularity: The Political Business Cycle Reexamined." American Journal of Political Science. 24 (1980). 696-714.

Kernell, Samuel. "Explaining Presidential Popularity." American Political Science Review. 72 (1978). 506-522.

Kmenta, Jan. Elements of Econometrics. New York: Macmillan Publishing Company, 1986.

Lipsey, Richard G. "Structural and Deficient-Demand Unemployment Reconsidered." In A. M. Ross (ed.). Employment Policy and The Labor Market. University of California Press, 1965. 210-255.

MacKuen, Michael B. "Political Drama, Economic Conditions, and the Dynamics of Presidential Popularity." American Journal of Political Science. 27 (1983). 165-192.

MacRae, C. Duncan. "A Political Model of the Business Cycle" Journal of Political Economy. 85 (1977). 239-263.

Monroe, Kristen Renwick. Presidential Popularity and the Economy. New York: Praeger, 1984.

Mueller, John E. "Presidential Popularity from Truman to Johnson." American Political Science Review. 64 (1970). 18-34.

Nordhaus, William H. "The Political Business Cycle." Review of Economic Studies. 42 (1975). 169-189. 
Norpoth, Helmut and Thom Yantek. "Macroeconomic Conditions and Fluctuations of Presidential Popularity: The Question of Lagged Effects." American Journal of Political Science. 27 (1983). 785-807.

Ostrom, Charles W. and Dennis M. Simon. "Promise and Performance: A Dynamic Model of Presidential Popularity." American Political Science Review. 79 (1985). 334-358.

Peston, M. H. Theory of Macroeconomic Policy. New York: John Wiley and Sons, 1984.

Shapiro, Robert Y. and Bruce M. Conforto. "Presidential Performance, the Economy, and the Public's Evaluation of Economic Conditions." Journal of Politics. 42 (1980). 49-67.

Smyth, David J. and Pami Dua. "Public Perceptions of Macroeconomic Policy: An Econometric Analysis of the Reagan Presidency." Review of Economics and Statistics. 70 (1988). 357-361. and —. "The Public's Indifference Map Between Inflation and Unemployment: Empirical Evidence for the Nixon, Ford, Carter and Reagan Presidencies." Public Choice. 60 (1989). 71-85. , Susan K. Washburn, and Pami Dua. "Social Preferences, Inflation, Unemployment, and Political Business Cycles: Econometric Evidence for the Reagan Presidency." Southern Economic Journal. 56 (1989). 336-348. , Susan Washburn Taylor, and Pami Dua. "Structural Change in the United States Social Preference Function, 1953-1988." Applied Economics. (1990 Forthcoming). 